\title{
STATUS OF THE MAX-III STORAGE RING
}

\author{
G. LeBlanc, Å. Andersson, M. Demirkan, M. Eriksson, L-J. Lindgren, H. Tarawneh, S. Werin, \\ MAX-lab, Sweden \\ B. Anderberg, AMACC, Sweden
}

\begin{abstract}
The MAX-III storage ring[1] is a $700 \mathrm{MeV}$ machine intended to provide UV and IR radiation. The novel magnet design provides a compact lattice. The magnetic measurements of the first cell will be presented and compared with calculations.
\end{abstract}

\section{INTRODUCTION}

A $700 \mathrm{MeV}$ storage ring for synchrotron radiation is being built at MAX-lab. The ring is optimized for the UV spectral region and will also provide IR radiation. The lattice is compact, with combined function magnets. The magnets are integrated into the support structure providing for ease of alignment. The magnet structure is designed with $2 \mathrm{D} / 3 \mathrm{D}$ magnetic field programs and the results are compared with measurements on the first prototype magnet structure.

The ring has 8 cells. Space constraints have led to a compact ring with only two families of magnets, a quadrupole and a bending magnet. The lattice parameters are given in table 1.

Table 1: Lattice Parameters

\begin{tabular}{|l|l|}
\hline Horizontal tune & 3.80 \\
\hline Vertical tune & 2.85 \\
\hline Energy & $700 \mathrm{MeV}$ \\
\hline Horizontal emittance & $13 \mathrm{~nm} \mathrm{rad}$ \\
\hline Ring circumference & $36 \mathrm{~m}$ \\
\hline Momentum compaction factor & 0.033 \\
\hline Dispersion in straight sections & $0.46 \mathrm{~m}$ \\
\hline Periodicity & 8 \\
\hline Straight section length & $2.45 \mathrm{~m}$ \\
\hline
\end{tabular}

The magnet structure is complex in the way that all magnets share the same yoke. Cross-talk between the different magnet families within the cell is studied with a 3D magnetic field code. The magnetic lengths for different multipoles are calculated and the final pole face profiles are corrected to give the right integrated strengths.

\section{THE MAGNET BLOCK}

The magnet is solid iron and the bending magnet poles, coil slots, and surfaces for quadrupole poles are machined out of a block. The quadrupole poles are made separately and bolted to the block, which serves as the return yoke. The bending magnet has an integrated gradient and specially formed ends to give a sextupole component. Pole-face windings are used to control both the quadrupole and sextupole components of the magnetic field. The quadrupoles have an integrated sextupole component, as well as seperate coils to adjust it.
Additional coils on the quadrupole poles will be used for orbit correction.

The desired magnetic components are calculated using the hard edge model for the magnetic lengths. Figure 1 shows the lower half of the magnet block. The design magnet parameters are shown in table 2, where the chromaticity is set to 1 in both planes.

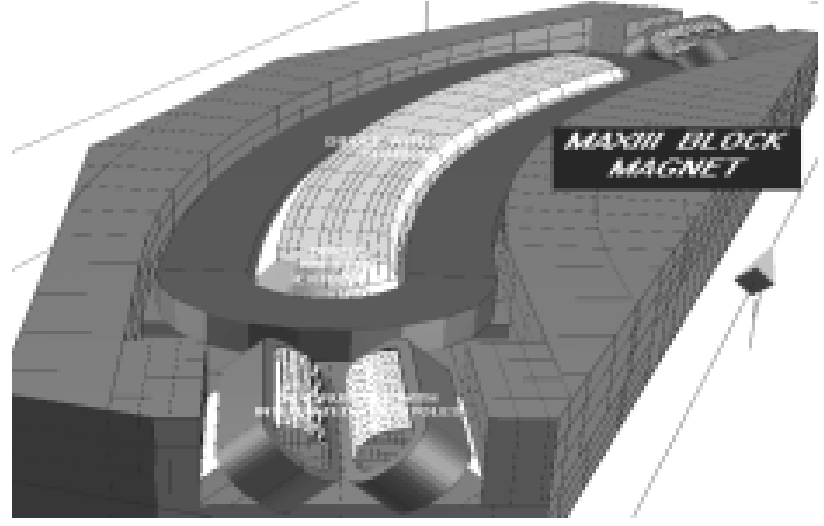

Figure 1: Lower half of a magnet block.

Table 2: Design Magnet Parameters

\begin{tabular}{|l|l|l|l|}
\hline \multicolumn{2}{|c|}{ Bending Magnet } & \multicolumn{2}{c|}{ Quadrupole } \\
\hline $\mathrm{L}$ & $1.25 \mathrm{~m}$ & $\mathrm{~L}$ & $0.2 \mathrm{~m}$ \\
\hline$\rho$ & $1.59 \mathrm{~m}$ & --- & --- \\
\hline $\mathrm{B}$ & $1.46709 \mathrm{~T}$ & --- & --- \\
\hline $\mathrm{K}$ & $3.52277 \mathrm{~T} / \mathrm{m}$ & $\mathrm{K} 1$ & $13.9862 \mathrm{~T} / \mathrm{m}$ \\
\hline $\mathrm{S} * \mathrm{~L}$ & $-8.73085 \mathrm{~T} / \mathrm{m}$ & $\mathrm{S}$ & $30.72434 \mathrm{~T} / \mathrm{m}^{2}$ \\
\hline
\end{tabular}

\section{CALCULATIONS}

\section{Bending Magnet}

Initially, the pole profile for the bending magnet is designed using a 2-dimensional program[1]. The program is used to form the edges to give the final field components and reduce higher order multipoles. The resulting field is shown in figure 2 .

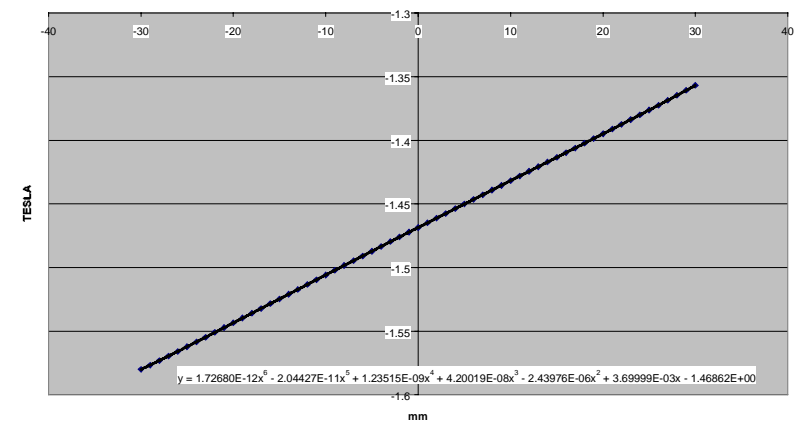

Figure 2: Field in the bending magnet. 
The residual field, containing higher order multipole components, is shown in figure 3 .

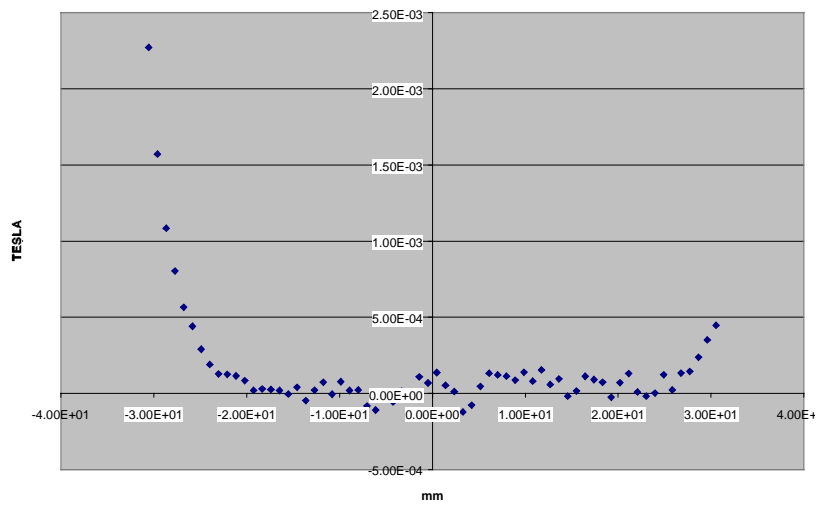

Figure 3: Residual multipoles in the bending magnet.

The bending magnet end is formed to give one of the sextupole components of the structure. The integrated sextupole field is calculated in RADIA[2]. The result is shown in figure 4.

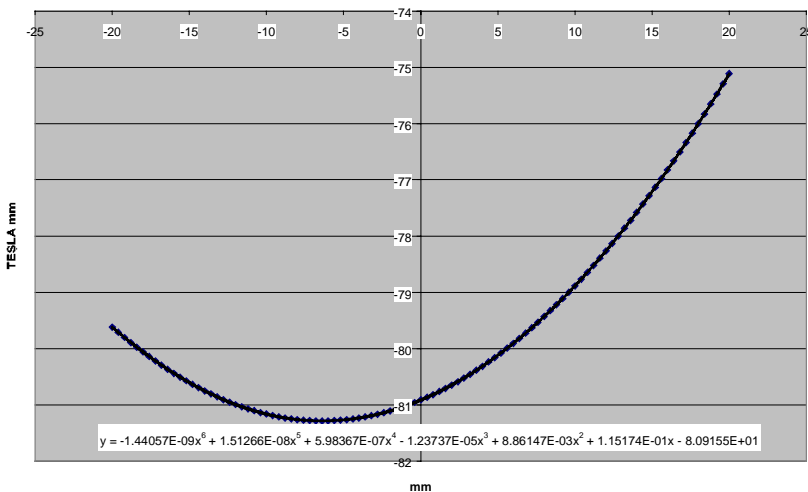

Figure 4: Integrated sextupole field in the bending magnet.

\section{Magnetic Lengths}

From the calculations shown, we determine the magnetic lengths. The dipole and gradient fields at the midpoint of the magnet, together with the integrals over the model magnet makes it possible to extract the magnetic lengths for different multipoles. The values for the bending magnet are:

- Dipole length: $\mathrm{L}_{\mathrm{dip}}=1249.6 \mathrm{~mm}$

- Gradient length: $\mathrm{L}_{\mathrm{q}}=1198.0 \mathrm{~mm}$

These lengths are compared to the hard edge length $1250 \mathrm{~mm}$. By varying the mechanical length, the dipole length can be adjusted. The deviation in the gradient length is corrected by increasing the gradient value until the integrated strength equals the lattice value as previously described.

\section{Sextupole Component}

The pole end is formed to give the desired integrated sextupole strength and the other multipoles are minimised. The result is shown in figure 3 . The residual fields correspond to less than 1 gauss at $+/-20 \mathrm{~mm}$ in the bulk field. The integrated sextupole field is $\mathrm{S} * \mathrm{Ls}=8.9$ $\mathrm{T} / \mathrm{m}$.

\section{Quadrupole}

The calculations for the quadrupole with integrated sextupole component are similar to that of the bendsection. The results for the extracted multipoles of the quadrupole are:

- Mechanical length $=170 \mathrm{~mm}$

- Quadrupole length $=200 \mathrm{~mm}$

- Sextupole length $=190 \mathrm{~mm}$

\section{Corrections due to Cross-talk}

The integration of several magnetic elements in a single block gives rise to coupling between the magnetic circuits. In the present design, we have found that the return flux from the bending magnet gives rise to a small dipole and sextupole component in the quadrupole region. In these calculations the magnet model is simplified due to the large memory requirements for the detailed model. The cross-talk effect was calculated in the simplified version of the cell as shown in fig.5.

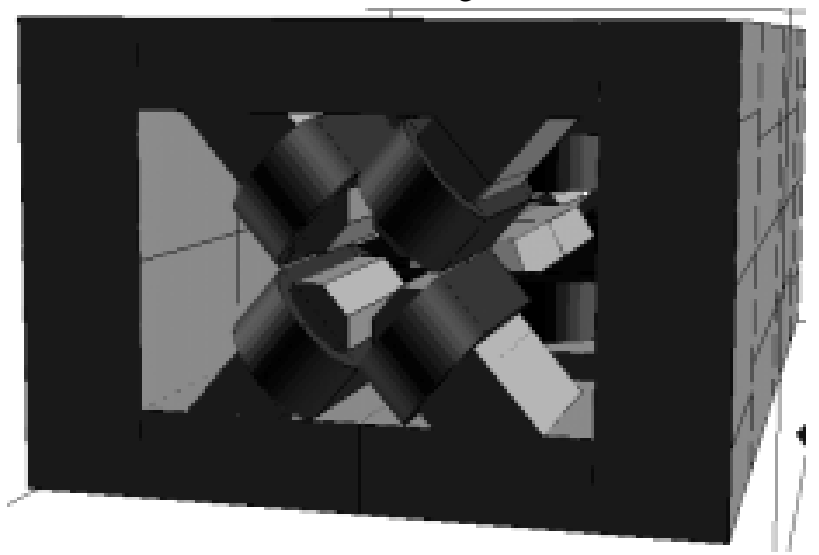

Figure 5: Simplified model used for cross-talk calculations.

The resulting integral field in the quadrupole region due to the return flux from the bending magnet field is shown

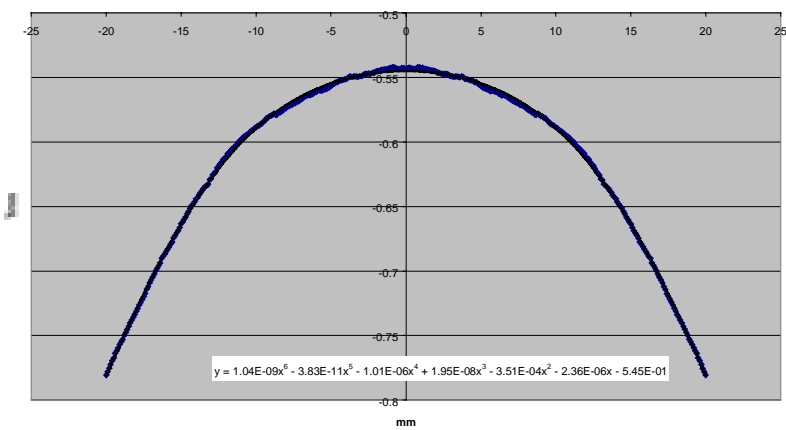

in figure 6.

Figure 6: Integrated field in quadrupole region.

The main component that needs to be corrected for is that part that goes through the quadrupole poles. For the prototype cell, the sextupole component is corrected for with the number obtained from these calculations. The normal corrector magnets will correct for the small dipole component of the cross-talk field. 
A polynomial fit of the integral gives the sextupole strength, $\mathrm{S} * \mathrm{~L}=-0.35 \mathrm{~T} / \mathrm{m}$. For an effective sextupole length of $190 \mathrm{~mm}$ for the quadrupole, the integrated sextupole component should be corrected by $0.35 / 0.19=1.84 \mathrm{~T} / \mathrm{m}^{2}$. The cross-talk sextupole component is of the opposite sign of the designed sextupole component, so this value is added to the initial value.

\section{Results of Model Simulations}

Table 2 compares the design values for the bending magnet field with those achieved in the model after correcting for the magnetic lengths of the different components.

Table 2: Comparison of design and model values for bending magnet.

\begin{tabular}{|l|c|c|}
\hline \multicolumn{3}{|c|}{ Bending Magnet: $1.46709 \mathrm{~T}, 1250 \mathrm{~mm}$ designed } \\
\hline & Design & Model \\
\hline $\mathrm{K} * \mathrm{~L}_{\mathrm{K}}$ & $3.52 * 1.25=4.4 \mathrm{~T}$ & $3.67 * 1.198=4.397 \mathrm{~T} / \mathrm{m}$ \\
\hline $\mathrm{S} * \mathrm{~L}$ & $8.73 \mathrm{~T} / \mathrm{m}$ & $8.9 \mathrm{~T} / \mathrm{m}$ \\
\hline
\end{tabular}

Table 3 compares the design values for the quadrupole field with those of the model after correcting for magnetic lengths. and cross-talk from the bending magnet.

Table 3: Comparison of design and model values for quadrupole.

\begin{tabular}{|c|c|c|}
\hline \multicolumn{3}{|c|}{ Quadrupole: $13.99 \mathrm{~T} / \mathrm{m}, 200 \mathrm{~mm}$ designed } \\
\hline & Design & Model \\
\hline $\mathrm{S} * \mathrm{~L}_{\mathrm{S}}$ & $30.7 * 0.2=6.14 \mathrm{~T} / \mathrm{m}$ & $32.32 * 0.19=6.14 \mathrm{~T} / \mathrm{m}$ \\
\hline \multicolumn{2}{|c|}{ Cross-talk: $1.85 \mathrm{~T} / \mathrm{m}^{2} \rightarrow 34.17 * 0.19=6.49 \mathrm{~T} / \mathrm{m}$} \\
\hline
\end{tabular}

\section{PROTOTYPE MEASUREMENTS}

The prototype magnet was measured with a high quality Hall probe system. Measurements were made in the symmetry plane. The measurements start far outside the bending magnet and extend into the bend section where fields are stable.

When analysing the data in the measured field map it was found that the sextupole component decreases further into the magnet. This unexpected behaviour is caused by holes for mounting the pole-face windings to the pole. Since the initial value from the pole curvature is higher than designed, the extra holes for the pole-face windings can be used to trim the sextupole component to the design value. The behaviour of the integrated end sextupole component is shown in figure 7.

The cross-talk field from the bending magnet was measured in the quadrupole region outside the bending magnet. It turns out that the measured field is not as strong as was calculated in the model. An explanation could be that there are several cuts in the yoke that could not be included in the model calculations.

The quadrupole was mapped in the same way as the bending magnet.

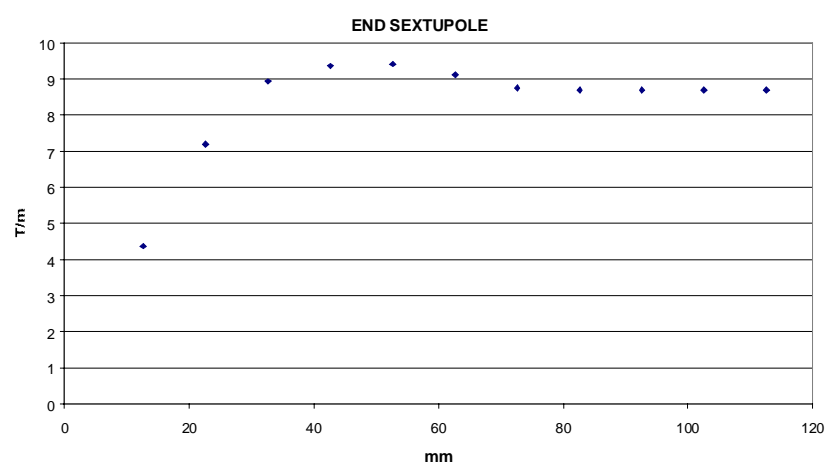

Figure 7: End sextupole in the bending magnet.

\section{RESULTS}

Table 4 shows the results of the magnetic measurements of the prototype MAX-III magnet fields. The values obtained from the model are in parentheses.

Table 4. Measured components of the bending magnet and quadrupole fields.

\begin{tabular}{|l|c|c|c|}
\hline \multicolumn{5}{|c|}{ Bending Magnet } \\
\hline & B & Gradient & Sextupole \\
\hline Strength & $1.467 \mathrm{~T}(1.467)$ & $\begin{array}{c}3.79 \mathrm{~T} / \mathrm{m} \\
(3.67)\end{array}$ & -------------- \\
& & $\begin{array}{c}4.53 \mathrm{~T} \\
(4.40)\end{array}$ & $\begin{array}{c}9.4-8.7 \mathrm{~T} / \mathrm{m} \\
(8.9)\end{array}$ \\
\hline $\begin{array}{l}\text { Integrated } \\
\text { strength }\end{array}$ & $\begin{array}{c}1.842 \mathrm{Tm} \\
(1.836)\end{array}$ & $\begin{array}{c}1.194 \mathrm{~m} \\
(1.198)\end{array}$ & -------------- \\
\hline Magnetic & $1.254 \mathrm{~m}$ & $(1.250)$ & Quadrupole \\
Length & \multicolumn{4}{|c|}{ Gradient } & $34.8 \mathrm{~T} / \mathrm{m}^{2}(33.9)$ \\
\hline \multicolumn{4}{|c|}{$6.59 \mathrm{~T} / \mathrm{m}(6.44)$} \\
\hline Strength & $13.98 \mathrm{~T} / \mathrm{m}(13.98)$ & $0.185 \mathrm{~m}(0.190)$ \\
\hline Integrated \\
strength
\end{tabular}

\section{CONCLUSIONS}

The measured magnetic field values for the prototype MAX III cell agree well with the designed values. The 3D code RADIA turns out to be a good tool for designing complex structures. The cross-talk seems to be overestimated in the code, but in this case the model had to be simplified since the real yoke contains a lot of cuts that could not be modelled. The holes for fitting the poleface windings in the bending magnet poles provided an excellent way to trim the value of the end-sextupole component. The strength of the pole-face windings of +$10 \%$ for all components is much more than is needed to reach the design values for the cell.

\section{REFERENCES}

[1] G. LeBlanc et.al. "MAX-III, a $700 \mathrm{MeV}$ Storage Ring for Synchrotron Radiation", EPAC2000, Vienna.

[2] D. Meeker; http://members.aol.com/dcm3c.

[3] http://www.esrf.fr/machine/support/ids/public/. 